\title{
Dominator Chromatic Number of Interval Graphs
}

\author{
A. Sudhakaraiah ${ }^{1}$ and V. Raghava Lakshmi ${ }^{2}$ \\ ${ }^{1}$ Department of Mathematics, S. V. University, Tirupati, Andhra Pradesh-517502, India \\ ${ }^{2}$ Department of S\&H (Mathematics), Vijaya Institute of Technology for Women, Vijayawada, Andhra Pradesh, \\ India - 521108
}

\begin{abstract}
The present paper concentrates on the theory of dominator coloring in graphs and focuses on resolving the dominator chromatic number of interval graphs. Some categorized interval graphs are selected in this process of study. To facilitate the study and to establish the results, emphasis is given to the analogy between the nature and coherence of the intervals, which in turn played an essential role in determining the dominator chromatic number of the interval graphs. An interval graph is a circular-arc graph that can be represented with a set of arcs that do not cover the entire circle. A dominator coloring of a graph $G$ is an assignment of colors to the vertices of $G$ such that no two adjacent vertices are assigned with the same color and every vertex dominates all vertices of at least one color class, where a color class is the set of all vertices, having the same color. The minimum number of colors required for a dominator coloring of $G$ is called the dominator chromatic number of $G$ and is denoted by $\chi_{d}(G)$.
\end{abstract}

Mathematics Subject Classification: 05C15

Keywords: Chromatic number, dominator chromatic number, interval graphs

\section{Introduction}

Unless otherwise specified, throughout the paper the graph $\mathrm{G}(\mathrm{V}, \mathrm{E})$ is a finite and connected graph with the vertex set $\mathrm{V}(\mathrm{G})$ and edge set $\mathrm{E}(\mathrm{G})$ and standard definitions of graph theory as found in [1] are followed.Graphs presented in this article are all finite and connected Interval Graphs.

Interval graphs are a special class of circular- arc graphs that can be represented with a set of arcs that do not cover the entire circle. The extensive study of interval graphs has been done for several decades by both mathematicians and computer scientists. Let $\mathrm{I}=\left\{\mathrm{I}_{1}, \mathrm{I}_{2}, \mathrm{I}_{3}, \ldots . ., \mathrm{I}_{\mathrm{k}}\right\}$ be an interval family, where each $\mathrm{I}_{\mathrm{i}}$ is an interval on the real line and $I_{i}=\left[a_{i}, b_{i}\right]$, for $i=1,2,3, \ldots, k$. Here $a_{i}$ is called the left end point and $b_{i}$ is called the right end point. Without loss of generality, one can assume that, all end points of the intervals are distinct numbers between 1 and $2 \mathrm{k}$.. The intervals are named in the increasing order of their left end points. The graph $\mathrm{G}(\mathrm{V}, \mathrm{E})$ is an interval graph if there is one-to-one correspondence between the vertex set $\mathrm{V}$ and the interval family I. Two vertices of $\mathrm{G}$ are joined by an edge if and only if their corresponding intervals in I intersect. That is if $I_{i}=\left[a_{i}, b_{i}\right]$ and $I_{j}=\left[a_{j}, b_{j}\right]$, then $I_{i}$ and $I_{j}$ will intersect if $a_{i}<b_{j}$ or $a_{j}<b_{i}$. Interval graphs are rich in combinatorial structures and have found applications in several disciplines such as traffic control, ecology, biology, computer sciences and particularly useful in cyclic scheduling and computers storage allocation problems etc. Having a representation of graph with intervals or arcs can be helpful in combinatorial problems of the graph, such as isomorphism testing and finding maximum independent set and cliques of graphs.

In section II, dominator chromatic number of some special classes of interval graphs is discussed. The dominator chromatic number of the graph $\mathrm{G}$ is the minimum number of colors required to properly color the graph, so that every vertex of the graph dominates an entire color class of the graph. Dominator chromatic number of the graph is denoted by $\chi_{\mathrm{d}}(\mathrm{G})$.

The concept of dominator chromatic number was introduced by Gera et al. [2]. Dominating Set and Coloring have a number of applications and this has led to the algorithmic study of numerous variants of these problems. A number of basic combinatorial and algorithmic results on DC have been obtained in [2], [3], [4] and [5]. A systematic study of dominator coloring problem from the perspective of algorithms and complexity was initiated in [6].

\section{Dominator chromatic numbers of Interval graphs}

Theorem 2.1: Let $I=\left\{I_{1}, I_{2}, I_{3}, \ldots . ., I_{k}\right\}$ be the interval family corresponding to an interval graph G. For any three consecutive intervals $I_{i}, I_{j}$ and $I_{k}$, if $I_{j}$ doesnot dominate any other interval except $I_{i}$ and $I_{k}$, then

$$
\begin{aligned}
\chi_{\mathrm{d}}(\mathrm{G}) & =1+[\mathrm{k} / 3] ; \text { for } \mathrm{k}=2,3,4,5,7 \\
& =2+[\mathrm{k} / 3] ; \text { otherwise }
\end{aligned}
$$

Proof: Let $G$ be the interval graph, whose interval family $I=\left\{I_{1}, I_{2}, I_{3}, \ldots . ., I_{k}\right\}$ satisfies the condition mentioned in the theorem. By the hypothesis,

the interval $\mathrm{I}_{1}$ intersects the interval $\mathrm{I}_{2}$; 
the interval $\mathrm{I}_{2}$ intersects the intervals $\mathrm{I}_{1}$ and $\mathrm{I}_{3}$; the interval $\mathrm{I}_{3}$ intersects the intervals $\mathrm{I}_{2}$ and $\mathrm{I}_{4}$; the interval $\mathrm{I}_{4}$ intersects the intervals $\mathrm{I}_{3}$ and $\mathrm{I}_{5}$;

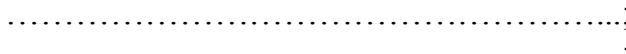

the interval $\mathrm{I}_{\mathrm{K}-2}$ intersects the intervals $\mathrm{I}_{\mathrm{K}-3}$ and $\mathrm{I}_{\mathrm{K}-1 ;}$

the interval $\mathrm{I}_{\mathrm{K}-1}$ intersects the intervals $\mathrm{I}_{\mathrm{K}-2}$ and $\mathrm{I}_{\mathrm{K}}$;

the interval $\mathrm{I}_{\mathrm{k}}$ intersects the interval $\mathrm{I}_{\mathrm{K}-1}$.

Let $v_{1}, v_{2}, v_{3}, \ldots, v_{k}$ be the vertices corresponding to the intervals $I_{1}, I_{2}, I_{3}, \ldots ., I_{k}$ respectively. It follows that, nbd $\left[\mathrm{v}_{\mathrm{i}}\right]=\left\{\mathrm{v}_{\mathrm{i}-1}, \mathrm{v}_{\mathrm{i}}, \mathrm{v}_{\mathrm{i}+1}\right\}$ for $\mathrm{i}=2,3, \ldots \ldots, \mathrm{k}-1$; nbd $\left[\mathrm{v}_{1}\right]=\left\{\mathrm{v}_{1}, \mathrm{v}_{2}\right\}$ and nbd $\left[\mathrm{v}_{\mathrm{k}}\right]=\left\{\mathrm{v}_{\mathrm{k}-1}, \mathrm{v}_{\mathrm{k}}\right\}$, where

nbd $\left[v_{i}\right]=\left\{\right.$ the set of all vertices adjacent to $\left.v_{i}\right\} \cup\left\{v_{i}\right\}$. Implies, $G$ is a path graph. Hence, by [2]

$$
\begin{aligned}
\chi_{\mathrm{d}}(\mathrm{G}) & =1+[\mathrm{k} / 3] ; \text { for } \mathrm{k}=2,3,4,5,7 \\
& =2+[\mathrm{k} / 3] ; \text { otherwise. }
\end{aligned}
$$

Illustration 2.1.1: Let the interval family $I=\{1,2,3, \ldots ., 8\}$ corresponding to the interval graph $G$ be as follows:

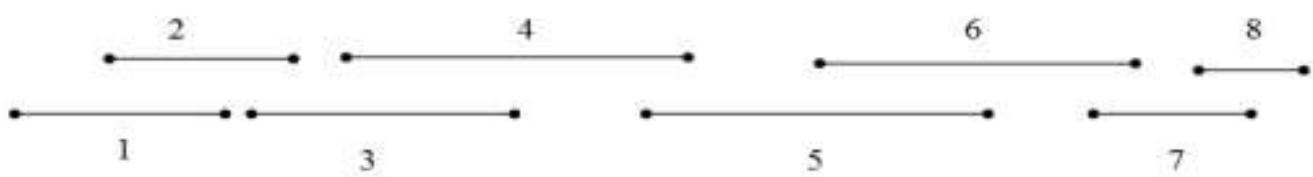

Clearly the interval family satisfies the conditions mentioned in the theorem 2.1 for $\mathrm{k}=8$. Therefore the dominator chromatic number of the graph $\mathrm{G}$ is $2+[8 / 3]$ i.e., 4 .

Verification: Let $\mathrm{V}_{1}, \mathrm{~V}_{2}, \ldots \ldots \ldots, \mathrm{V}_{8}$ be the vertices of the interval graph $\mathrm{G}$ corresponding to the intervals $1,2,3, \ldots ., 8$ respectively. In this case, the graph $\mathrm{G}$ will be as follows:

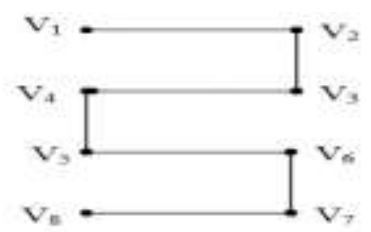

Clearly the vertices form a path graph. Hence by [2]

$$
\begin{aligned}
\mathrm{X}_{\mathrm{d}}(\mathrm{G}) & =2+[\mathrm{k} / 3] ; \text { for } \mathrm{k}=8 \\
& =2+[8 / 3] \\
& =4
\end{aligned}
$$

Theorem 2.2: In the family of intervals $I=\left\{I_{1}, I_{2}\right.$, suppose that no other intersections are observed except the following:

(i) $I_{i}$ intersects no other interval except $I_{i-1}$ which contains only the interval $I_{i}$

(ii) $\mathrm{I}_{\mathrm{i}}$ intersects no other non contained intervals except $\mathrm{I}_{\mathrm{i}}-2,2$ and $\mathrm{I}_{\mathrm{i}+2}$

$$
\text { for } \mathrm{i}=2,4,6, \ldots, 2 \mathrm{k} \text { and }
$$

for $\mathrm{i}=3,5,7, \ldots, 2(\mathrm{k}-2)+1$

Then, $\chi_{\mathrm{d}}(\mathrm{G})=\mathrm{k}+1$ for $\mathrm{k} \geq 3$, where $\mathrm{k} \in \mathrm{N}$

Proof: Let the interval family $I=\left\{I_{1}, I_{2}\right.$, conditions mentioned in the theorem.

By first condition stated in the theorem

$I_{2}$ intersects no other interval except $I_{1}$;

$\mathrm{I}_{4}$ intersects no other interval except $\mathrm{I}_{3}$;

$\mathrm{I}_{6}$ intersects no other interval except $\mathrm{I}_{5}$;

....................................;

$\mathrm{I}_{2 \mathrm{k}}$ intersects no other interval except $\mathrm{I}_{2 \mathrm{k}-1}$;

Every dominating set of $G$ contains either $I_{i}$ or $I_{i-1}$ for $i=2,4,6, \ldots, 2 k$. As a result, the set of intervals $\left\{\mathrm{I}_{1}, \mathrm{I}_{3}, \ldots ., \mathrm{I}_{2 \mathrm{k}-1}\right\}$ and $\left\{\mathrm{I}_{2}, \mathrm{I}_{4}, \ldots \ldots, \mathrm{I}_{2 \mathrm{k}}\right\}$ are minimal dominating sets of the graph $\mathrm{G}$. It follows that, $\gamma(\mathrm{G})=\mathrm{K}$.

By the first and second conditions stated in the theorem

$\mathrm{I}_{1}$ intersects no other interval except $\mathrm{I}_{2}$ and $\mathrm{I}_{3}$

$\mathrm{I}_{3}$ intersects no other interval except $\mathrm{I}_{1}, \mathrm{I}_{4}$ and $\mathrm{I}_{5}$; 
$\mathrm{I}_{5}$ intersects no other interval except $\mathrm{I}_{3}, \mathrm{I}_{6}$ and $\mathrm{I}_{7}$;

..................................;

$\mathrm{I}_{2 \mathrm{k}-3}$ intersects no other interval except $\mathrm{I}_{2 \mathrm{k}-5,} \mathrm{I}_{2 \mathrm{k}-2}$ and $\mathrm{I}_{2 \mathrm{k}-1}$

$\mathrm{I}_{2 \mathrm{k}-1}$ intersects no other interval except $\mathrm{I}_{2 \mathrm{k}-3}$, and $\mathrm{I}_{2 \mathrm{k}}$;

Partition the whole set of intervals $I$ into two subsets $A$ and $B$, where $A=\left\{I_{1}, I_{3}, I_{5}, \ldots \ldots \ldots, I_{2 k-1}\right\}$ and $\mathrm{B}=\left\{\mathrm{I}_{2}, \mathrm{I}_{4}, \ldots \ldots \ldots, \mathrm{I}_{2 \mathrm{k}}\right\}$. Assign colors $\mathrm{C}_{1}, \mathrm{C}_{2}, \mathrm{C}_{3}, \ldots \ldots, \mathrm{C}_{\mathrm{k}}$ to the intervals $\mathrm{I}_{1}, \mathrm{I}_{3}, \mathrm{I}_{5}, \ldots \ldots \ldots, \mathrm{I}_{2 \mathrm{k}-1}$ respectively of the set $A$. The set of intervals $\left\{I_{2}, I_{4}, \ldots \ldots \ldots, I_{2 k}\right\}$ is independent set of intervals. The same color, say $C_{k+1}$ that is different from the set of colors $C_{1}, C_{2}, C_{3}, \ldots, C_{k}$ can be assigned to every interval in the set of intervals $B$. The coloring is a proper coloring. Every interval in the independent set of intervals $\mathrm{B}$ dominates at least one color class in the set of color classes $C_{1}, C_{2}, C_{3}, \ldots ., C_{k}$ as the graph $G$ is a connected graph. Every color class corresponding to the intervals of set $\mathrm{A}$ consists of only one interval. As a result, every interval of $\mathrm{A}$ dominates its own color class. It follows that the coloring of the graph is a dominator coloring of the graph. Implies, $\chi_{\mathrm{d}}(\mathrm{G}) \leq \mathrm{k}+1$.

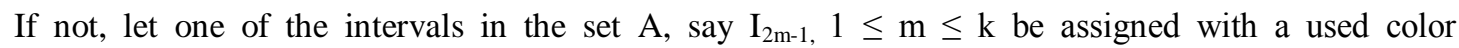
$\mathrm{C}_{\mathrm{p}}$, where $1 \leq \mathrm{p} \leq \mathrm{k}$ instead of the color $\mathrm{C}_{\mathrm{m}}$. The coloring is not a dominating coloring. In this case, the interval $\mathrm{I}_{2 \mathrm{~m}}$ can neither dominate the color class $\mathrm{C}_{\mathrm{k}+1}$, as it contains all the intervals of the set $\mathrm{B}$ which are not dominated by the interval $\mathrm{I}_{2 \mathrm{~m}}$ nor the color class $\mathrm{C}_{\mathrm{p}}$ as the color class $\mathrm{C}_{\mathrm{p}}$ contains the intervals $\mathrm{I}_{2 \mathrm{p}-1}$ and $\mathrm{I}_{2 \mathrm{~m}-1}$, among which, $\mathrm{I}_{2 \mathrm{p}-1}$ is not dominated by $\mathrm{I}_{2 \mathrm{~m}}$. That is at least $\mathrm{k}$ different colors are needed to color the $\mathrm{k}$ intervals of the set $\mathrm{A}$ and another new color for the intervals in the set B. Implies, $\chi_{\mathrm{d}}(\mathrm{G}) \geq \mathrm{k}+1$. Hence, $\chi_{\mathrm{d}}(\mathrm{G})=\mathrm{k}+1$.

Illustration 2.2.1: Let the interval family $I=\{1,2,3, \ldots, 8\}$ corresponding to the interval graph $G$ be as follows:

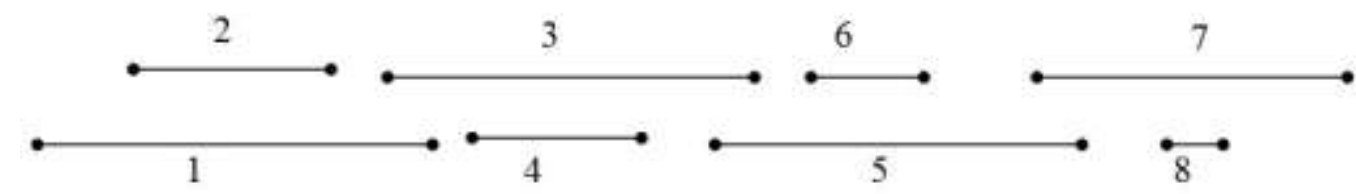

Clearly the interval family satisfies the conditions mentioned in the theorem 2.2 for $k=4$. Therefore the dominator chromatic number of the graph $\mathrm{G}$ is $\mathrm{k}+1$ i.e., 5

Verification: Let $\mathrm{V}_{1}, \mathrm{~V}_{2}, \ldots \ldots \ldots, \mathrm{V}_{8}$ be the vertices of the interval graph $\mathrm{G}$ corresponding to the intervals $1,2,3, \ldots ., 8$ respectively. In this case, the graph $\mathrm{G}$ will be as follows:

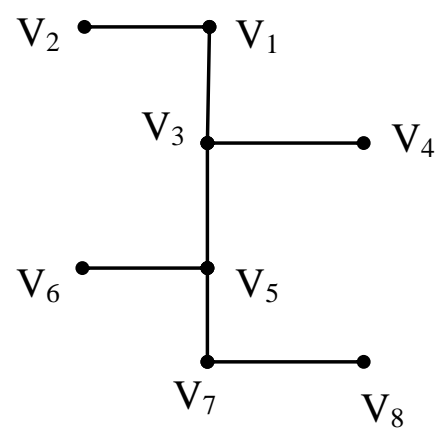

Clearly the vertices $\mathrm{V}_{1}, \mathrm{~V}_{3}, \mathrm{~V}_{5} \& \mathrm{~V}_{7}$ form a path graph. At least these four vertices must receive their unique color and one more color is needed for the rest of the vertices. Hence, $\chi_{d}(G)=4+1=5$.

Theorem 2.3 : In the family of intervals $I=\left\{I_{1}, I_{2}, \ldots \ldots \ldots, I_{3 k}\right\}$ corresponding to the Interval graph $G$, suppose that no other intersections are observed except the following:

(i) The non-intersecting intervals $I_{i}$ and $I_{i-1}$ intersect no other interval except $I_{i-2}$ which contains only the intervals $I_{i}$ and $I_{i-1}$, for $i=3,6,9, \ldots, 3 \mathrm{k}$ and

(ii) $I_{i}$ intersects no other non contained intervals except $I_{i}-{ }_{3}$ and $I_{i+3}$,

$$
\text { for } \mathrm{i}=4,7,11, \ldots, 3(\mathrm{k}-2)+1
$$

Then, $\chi_{\mathrm{d}}(\mathrm{G})=\mathrm{k}+1$ for $\mathrm{k} \geq 3$, where $\mathrm{k} \in \mathrm{N}$

Proof : Let the interval family $I=\left\{I_{1}, I_{2}\right.$, conditions mentioned in the theorem. $\left.I_{3 k}\right\}$ corresponding to the interval family $G$ satisfy the 
By first condition stated in the theorem

$\mathrm{I}_{2}$ and $\mathrm{I}_{3}$ intersect no other interval except $\mathrm{I}_{1}$;

$\mathrm{I}_{5}$ and $\mathrm{I}_{6}$ intersect no other interval except $\mathrm{I}_{4}$;

$\mathrm{I}_{8}$ and $\mathrm{I}_{9}$ intersect no other interval except $\mathrm{I}_{7}$

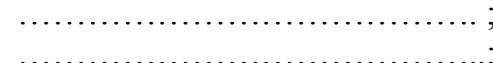

$\mathrm{I}_{3 \mathrm{k}}$ and $\mathrm{I}_{3 \mathrm{k}-1}$ intersect no other interval except $\mathrm{I}_{3 \mathrm{k}-2}$;

Every dominating set of $G$ contains $I_{i}$, for $i=1,4,7, \ldots, 3 \mathrm{k}-2$. As a result, the set of intervals $\left\{\mathrm{I}_{1}, \mathrm{I}_{4}, \ldots \ldots, \mathrm{I}_{3 \mathrm{k}-2}\right\}$ is a minimum dominating set of the graph $\mathrm{G}$. It follows that $\gamma(\mathrm{G})=\mathrm{K}$.

By the first and second conditions stated in the theorem

$\mathrm{I}_{1}$ intersects no other interval except $\mathrm{I}_{2}, \mathrm{I}_{3}$ and $\mathrm{I}_{4}$;

$\mathrm{I}_{4}$ intersects no other interval except $\mathrm{I}_{1}, \mathrm{I}_{5}, \mathrm{I}_{6}$ and $\mathrm{I}_{7}$;

$\mathrm{I}_{7}$ intersects no other interval except $\mathrm{I}_{4}, \mathrm{I}_{8}, \mathrm{I}_{9}$ and $\mathrm{I}_{10}$;

................................ ;

$\mathrm{I}_{3 \mathrm{k}-5}$ intersects no other interval except $\mathrm{I}_{3 \mathrm{k}-8,} \mathrm{I}_{3 \mathrm{k}-4}, \mathrm{I}_{3 \mathrm{k}-3}$ and $\mathrm{I}_{3 \mathrm{k}-2}$;

$\mathrm{I}_{3 \mathrm{k}-2}$ intersects no other interval except $\mathrm{I}_{3 \mathrm{k}-5}, \mathrm{I}_{3 \mathrm{k}-1}$ and $\mathrm{I}_{3 \mathrm{k}}$;

Partition the whole set of intervals $I$ into two subsets $A$ and $B$, where $A=\left\{I_{1}, I_{4}, I_{7}, \ldots \ldots . ., I_{3 k-2}\right\}$ and $B=\left\{I_{2}, I_{3}, I_{5}, I_{6}, I_{8}, I_{9}, \ldots \ldots, I_{3 k-4}, I_{3 k-3}, I_{3 k-1}, I_{3 k}\right\}$. Assign colors $C_{1}, C_{2}, C_{3}, \ldots \ldots, C_{k}$ to the intervals in the set $A$. The set $\mathrm{B}$ is an independent set of intervals. The same color, say $\mathrm{C}_{\mathrm{k}+1}$ that is different from the set of colors $\mathrm{C}_{1}, \mathrm{C}_{2}, \mathrm{C}_{3}, \ldots \ldots, \mathrm{C}_{\mathrm{k}}$ can be assigned to every interval in the set of intervals $\mathrm{B}$. The coloring is a proper coloring. Every interval in the independent set of intervals $\mathrm{B}$ is dominated by at least one color class from the set of color classes $C_{1}, C_{2}, C_{3}, \ldots ., C_{k}$ as the graph $G$ is a connected graph. Every color class corresponding to the intervals of set A consists of only one interval. As a result, every interval of A dominates its own color class. It follows that the coloring of the graph is a dominator coloring of the graph. Implies, $\chi_{\mathrm{d}}(\mathrm{G}) \leq \mathrm{k}+1$ and as in theorem 2.2 it can be proved that the coloring is a minimum dominator coloring. As a result, $\chi_{d}(G)=k+1$

2. 3. 1 Illustration: Let the interval family $I=\{1,2,3, \ldots, 12\}$ corresponding to the interval graph $G$ be as follows:

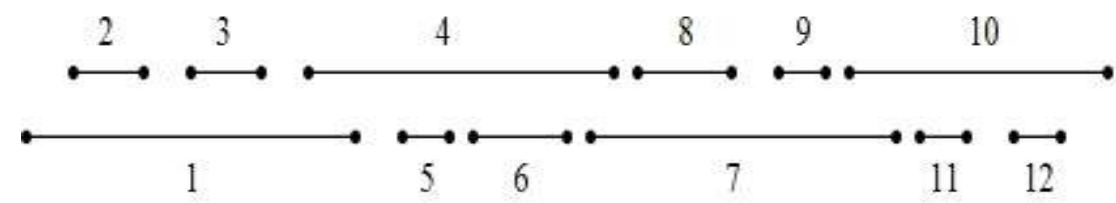

Clearly the interval family satisfies the conditions mentioned in the theorem 2.3 for $\mathrm{k}=4$. Therefore the dominator chromatic number of the graph $\mathrm{G}$ is $\mathrm{k}+1$ i.e., 5 .

Verification: Let $\mathrm{V}_{1}, \mathrm{~V}_{2}, \ldots, \mathrm{V}_{12}$ be the vertices of the interval graph $\mathrm{G}$ corresponding to the intervals $1,2,3, \ldots, 12$ respectively. In this case, the graph $\mathrm{G}$ will be as follows:

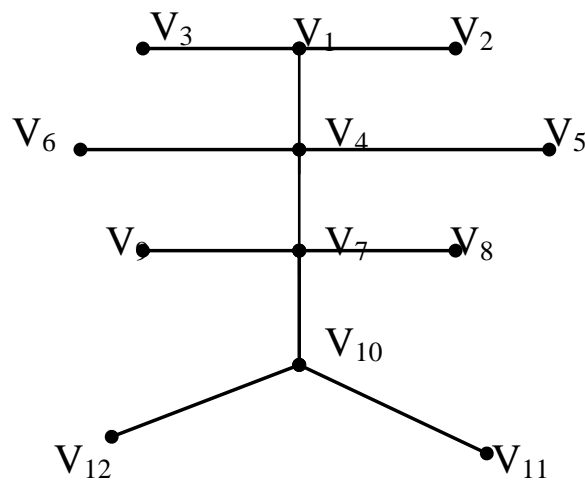

Clearly the vertices $\mathrm{V}_{1}, \mathrm{~V}_{4}, \mathrm{~V}_{7} \& \mathrm{~V}_{10}$ form a path graph. At least these four vertices must receive their unique color and one more color is needed for the rest of the vertices. Hence, it follows that $\chi_{\mathrm{d}}(\mathrm{G})=4+1=5$. 
2.4 Generalized Theorem: In the family of intervals $I=\left\{I_{1}, I_{2}\right.$, $\left.\mathrm{I}_{\mathrm{mk}}\right\}$ corresponding to the Interval graph G, suppose that no other intersections are observed except the following:

(i) The non-intersecting intervals $\mathrm{I}_{\mathrm{i}}, \mathrm{I}_{\mathrm{i}-1}, \mathrm{I}_{\mathrm{i}-2}, \ldots \ldots ., \mathrm{I}_{\mathrm{i}-(\mathrm{m}-2)}$ intersect no other interval except $\mathrm{I}_{\mathrm{i}-(\mathrm{m}-1)}$ which contains only the intervals $\mathrm{I}_{\mathrm{i}}, \mathrm{I}_{\mathrm{i}-1}, \mathrm{I}_{\mathrm{i}-2}, \ldots \ldots ., \mathrm{I}_{\mathrm{i}-(\mathrm{m}-2)}$ for $\mathrm{i}=\mathrm{m}, 2 \mathrm{~m}, 3 \mathrm{~m}, \ldots, \mathrm{km}$ and

(ii) $\mathrm{I}_{\mathrm{i}}$ intersects no other non contained intervals except $\mathrm{I}_{\mathrm{i}}-\mathrm{m}$ and $\mathrm{I}_{\mathrm{i}+\mathrm{m}}$ for $\mathrm{i}=\mathrm{m}+1,2 \mathrm{~m}+1,3 \mathrm{~m}+1, \ldots, \mathrm{m}(\mathrm{k}-2)+1$

Then, $\chi_{\mathrm{d}}(\mathrm{G})=\mathrm{k}+1$ for $\mathrm{k} \geq 3$, where $\mathrm{m}, \mathrm{k} \in \mathrm{N}$

Proof : Let the interval family $I=\left\{I_{1}, I_{2}, \ldots \ldots . ., I_{m k}\right\}$ corresponding to the interval family G satisfy the conditions mentioned in the theorem.

By first condition stated in the theorem

$\mathrm{I}_{2}, \mathrm{I}_{3}, \mathrm{I}_{4}, \ldots . ., \mathrm{I}_{\mathrm{m}}$ intersect no other interval except $\mathrm{I}_{1}$;

$\mathrm{I}_{\mathrm{m}+2,} \mathrm{I}_{\mathrm{m}+3}, \mathrm{I}_{\mathrm{m}+4,}, \mathrm{I}_{\mathrm{m}+5}, \ldots \ldots, \mathrm{I}_{2 \mathrm{~m}}$ intersect no other interval except $\mathrm{I}_{\mathrm{m}+1}$;

$\mathrm{I}_{2 \mathrm{~m}+2,}, \mathrm{I}_{2 \mathrm{~m}+3}, \mathrm{I}_{2 \mathrm{~m}+4}, \mathrm{I}_{2 \mathrm{~m}+5}, \ldots \ldots \ldots, \mathrm{I}_{3 \mathrm{~m}}$, intersect no other interval except $\mathrm{I}_{2 \mathrm{~m}+1}$

.................................;

$\mathrm{I}_{(\mathrm{k}-1) \mathrm{m}+2}, \mathrm{I}_{(\mathrm{k}-1) \mathrm{m}+3} \mathrm{I}_{(\mathrm{k}-1) \mathrm{m}+4}, \ldots \ldots \ldots \ldots, \mathrm{I}_{\mathrm{km}}$ intersect no other interval except $\mathrm{I}_{(\mathrm{k}-1) \mathrm{m}+1}$

Every dominating set of $G$ contains $I_{i}$ for $i=1, m+1,2 m+1,3 m+1$, $(\mathrm{k}-1) \mathrm{m}+1$

As a result the set of intervals $\left\{\mathrm{I}_{1}, \mathrm{I}_{\mathrm{m}+1}, \mathrm{I}_{2 \mathrm{~m}+1}, \ldots . ., \mathrm{I}_{(\mathrm{k}-1) \mathrm{m}+1}\right\}$ is a minimum dominating set of the graph G. It follows that $\gamma(\mathrm{G})=\mathrm{K}$.

By the first and second conditions stated in the theorem

$\mathrm{I}_{1}$ intersects no other interval except $\mathrm{I}_{2}, \mathrm{I}_{3}, \ldots \ldots \ldots \ldots \ldots \ldots, \mathrm{I}_{\mathrm{m}}, \mathrm{I}_{\mathrm{m}+1}$;

$I_{m+1}$ intersects no other interval except $I_{1}, I_{m+2}, I_{m+3}, \ldots \ldots . ., I_{2 m}, I_{2 m+1}$

$\mathrm{I}_{2 \mathrm{~m}+1}$ intersects no other interval except $\mathrm{I}_{\mathrm{m}+1}, \mathrm{I}_{2 \mathrm{~m}+2}, \mathrm{I}_{2 \mathrm{~m}+3}, \ldots, \mathrm{I}_{3 \mathrm{~m}}, \mathrm{I}_{3 \mathrm{~m}+1}$

....................................;

$\mathrm{I}_{(\mathrm{k}-2) \mathrm{m}+1}$ intersects no other interval except $\mathrm{I}_{(\mathrm{k}-3) \mathrm{m}+1}, \mathrm{I}_{(\mathrm{k}-2) \mathrm{m}+2}, \mathrm{I}_{(\mathrm{k}-2) \mathrm{m}+3}, \ldots ., \mathrm{I}_{(\mathrm{k}-1) \mathrm{m}+1}$

$\mathrm{I}_{(\mathrm{k}-1) \mathrm{m}+1}$ intersects no other interval except $\mathrm{I}_{(\mathrm{k}-2) \mathrm{m}+1}, \mathrm{I}_{(\mathrm{k}-1) \mathrm{m}+2}, \mathrm{I}_{(\mathrm{k}-1) \mathrm{m}+3}, \ldots \ldots, \mathrm{I}_{\mathrm{km}}$

Partition the whole set of intervals I into two subsets $A$ and $B$, where $A=\left\{I_{1}, I_{m+1}, I_{2 m+1}, \ldots \ldots, I_{(k-1) m+1}\right\}$ and $B=\left\{I_{2}, I_{3}, \ldots, I_{m}, I_{m+2}, I_{m+3}, \ldots, I_{2 m}, \ldots ., I_{(k-1) m+2}, I_{(k-1) m+3}, \ldots, I_{k m}\right\}$. Assign colors $C_{1}, C_{2}, C_{3}, \ldots \ldots, C_{k}$ to the intervals in the set $A$. The set $B$ is an independent set of intervals. The same color, say $C_{k+1}$ that is different from the set of colors $\mathrm{C}_{1}, \mathrm{C}_{2}, \mathrm{C}_{3}, \ldots \ldots, \mathrm{C}_{\mathrm{k}}$ can be assigned to every interval in the set of intervals $\mathrm{B}$. The coloring is a proper coloring. Every interval in the independent set of intervals $\mathrm{B}$ is dominated by at least one color class from the set of color classes $\mathrm{C}_{1}, \mathrm{C}_{2}, \mathrm{C}_{3}, \ldots \ldots, \mathrm{C}_{\mathrm{k}}$ as the graph $\mathrm{G}$ is a connected graph. Every color class corresponding to the intervals of set A consists of only one interval. As a result, every interval of A dominates its own color class. It follows that the coloring of the graph is a dominator coloring of the graph. Implies, $\chi_{\mathrm{d}}(\mathrm{G}) \leq \mathrm{k}+1$ and as in theorem 2.2 it can be proved that the coloring is a minimum dominator coloring. As a result, $\chi_{\mathrm{d}}(\mathrm{G})=\mathrm{k}+1$

2.4.1 Illustration: Let the interval family $I=\{1,2,3, \ldots ., 15\}$ corresponding to the interval graph $G$ be as follows:

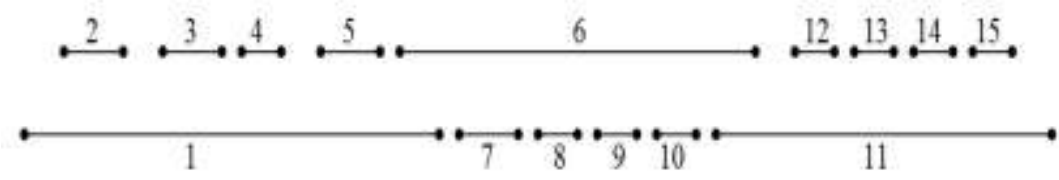

Clearly the interval family satisfies the conditions mentioned in the theorem 2.4 for $\mathrm{k}=3$ and $\mathrm{m}=5$. Therefore the dominator chromatic number of the graph $\mathrm{G}$ is $\mathrm{k}+1$ i.e., 4

Verification: Let $\mathrm{V}_{1}, \mathrm{~V}_{2}, \ldots, \mathrm{V}_{15}$ be the vertices of the interval graph $\mathrm{G}$ corresponding to the intervals $1,2,3, \ldots, 15$ respectively. In this case, the graph $\mathrm{G}$ will be as follows:

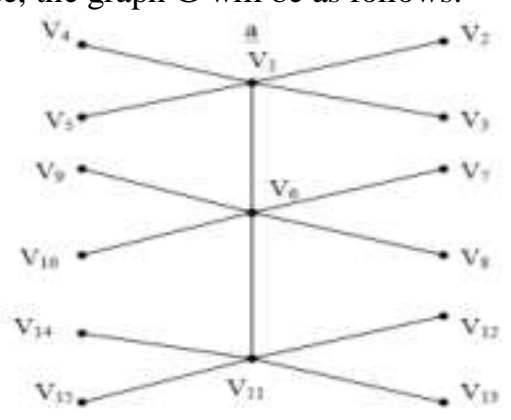


Clearly the vertices $\mathrm{V}_{1}, \mathrm{~V}_{6}, \& \mathrm{~V}_{11}$ form a path graph. At least these three vertices must receive their unique color and one more color is needed for the rest of the vertices. Hence, $\chi_{\mathrm{d}}(\mathrm{G})=3+1=4$.

\section{Conclusion}

Resolving the dominator chromatic number of some special classes of interval graphs has been the main focus of the paper. Especially, the nature of the arcs played a major role in determining the dominator chromatic number of the interval graphs with amazing ease. Some categorized graphs have been chosen in the process of exploration. In future, efforts will be put to identify the interval graphs with domination chromatic number equal to either domination number or chromatic number.

\section{Acknowledgement}

We are in debited to Dr. B. Maheshwari without whose valuable guidance this paper would not have been possible.

\section{References}

[1] F.Harrary, Graph Theory, Addition - Wesley Reading Mass, 1969.

[2] R. Gera, C. Rasmussen, and S. Horton. Dominator colorings and safe clique partitions, Congressus Numerantium, 181, $19-32,2006$.

[3] R. Gera. On dominator coloring in graphs. In Graph Theory Notes of New York, LII, 25-30, 2007.

[4] R. Gera. On the dominator colorings in bipartite graphs. In ITNG, IEEE, pages 1- 6, 2007.

[5] S. Hedetniemi, S. Hedetniemi, A. McRae, and J. Blair. Dominator colorings of graphs. Preprint, 2006.

[6] S. Arumugam, On dominator coloring in graphs, IWGC, BDU, 2010. 